\title{
Prognostic Factors for Pancreatic Cancer Patients Treated with Immune-cell Therapy
}

\author{
KAORI MAKITA ${ }^{1}$, TAKASHI KAMIGAKI ${ }^{1,2}$, SACHIKO OKADA ${ }^{1}$, ERIKO MATSUDA ${ }^{1}$, HIROSHI IBE ${ }^{1}$, \\ ERI OGUMA ${ }^{1}$, KEIKO NAITOH $^{1}$, RISHU TAKIMOTO $^{1,2}$ and SHIGENORI GOTO ${ }^{1,2}$ \\ ${ }^{1}$ Seta Clinic Group, Tokyo, Japan; \\ ${ }^{2}$ Department of Next Generation Cell and Immune therapy, \\ Graduate School of Medicine, Juntendo University, Tokyo, Japan
}

\begin{abstract}
Background/Aim: The past 17 years, immune-cell therapy has been administered to 990 patients with advanced or recurrent pancreatic adenocarcinoma and 50 patients with curatively resected pancreatic adenocarcinoma. Materials and Methods: The correlation between overall survival (OS) and various factors including sex, age, performance status (PS), distant metastasis, chemotherapy, radiotherapy, and type of immune-cell therapy were evaluated by univariate and multivariate analyses. Results: The median OS of advanced or recurrent pancreatic cancer was 5.8 months, and the prognosis was improved in pancreatic cancer patients who received immune-cell therapy with $P S$ scores of $0-1$ [hazard risk $(H R)=0.56 ; 95 \%$ confidence interval $(C I)=0.46-0.68 ; \quad p<0.0001]$, chemotherapy $(H R=0.68 ; 95 \% C I=0.54-0.87 ; p=0.002)$, or radiotherapy $(H R=0.76 ; 95 \% C I=0.63-0.93 ; p=0.006)$. Multivariate analysis demonstrated that distant metastasis indicated a poor prognosis for pancreatic cancer patients that were administered immune-cell therapy $(H R=1.62$; 95\%CI=1.37-1.93; $p<0.0001)$. Additionally, the combined immune-cell therapy with $\alpha \beta$ T cell and dendritic cell $(D C)$ vaccine provided a survival benefit in advanced or recurrent pancreatic cancer patients $(H R=0.69 ; 95 \% C I=0.57-0.83$; $p<0.0001)$. Conclusion: A survival benefit could be potentially obtained with better PS by the combination of $\alpha \beta$ $T$ cell therapy, $D C$ vaccine therapy, and chemotherapy at an early stage in pancreatic cancer.
\end{abstract}

Correspondence to: Kaori Makita, Director, Seta Clinic Osaka, Seta Clinic Group, 5-14-13 Esaka, Suita-shi, Osaka 564-0063, Japan. Tel: +81663780086, Fax: +81663780088, e-mail: makita@jimmunother.com

Key Words: Immune-cell therapy, pancreatic cancer, prognostic factors, $\alpha \beta \mathrm{T}$ cell therapy, dendritic cell vaccine.
Pancreatic cancer is a refractory disease with nearly the same number of newly diagnosed and deceased patients each year. From all the pancreatic cancer patients only $10 \%-20 \%$ can undergo surgery, because many of them are often diagnosed with an advanced stage of the disease (1). For a long time now, gemcitabine (GEM) has been regarded as a standard anticancer agent for unresectable pancreatic cancer (2). In 2011, a study showed that the median survival time (MST) (11.1 months) of patients treated with FOLFIRINOX (oxaliplatin, irinotecan, leucovorin, and fluorouracil) was significantly longer than that with GEM alone (6.8 months) even though it had high toxicity (3). Another comparative study (Metastatic Pancreatic Adenocarcinoma Clinical Trial: MPACT trial) showed that the MST was 8.5 months for the combination of GEM and albumin-bound paclitaxel (nabpaclitaxel) as compared with 6.7 months for GEM alone (4).

Not only chemotherapy, but also immune-cell therapy against malignancies has been developed. Between 2007 and 2012, a randomized controlled trial of adjuvant chemoimmunotherapy with activated killer $\mathrm{T}$ cells and dendritic cells (DCs) versus chemotherapy was performed on 103 postsurgical non-small cell lung cancer patients. The study showed that the 2- and 5-year survival rates were significantly increased to $93.4 \%$ and $81.4 \%$ in the chemoimmunotherapy group compared to $66.0 \%$ and $48.3 \%$ in the control group, respectively (5). A historical cohort study of advanced lung cancer patients also showed that combination of immune-cell therapy and chemotherapy increased MST (20.8 months) compared with chemotherapy alone (15.7 months) (6). Furthermore, in a comprehensive immunotherapy combined with intratumoral injection of zoledronate-pulsed DCs, adoptive T cell infusion, and GEM for unresectable pancreatic cancer patients, 7 of 15 patients showed a stable disease (SD) and a significantly increased $\mathrm{CD}^{+} /$Treg ratio after the treatment. The MST and progression-free survival of the 15 patients were 12.0 months and 5.5 months, respectively. It was considered that a more 
beneficial immunotherapy could be achieved by using accurate and suitable biomarkers such as $\mathrm{CD}^{+} /$Treg ratio and neutrophil/lymphocyte ratio (NLR) (7).

The Seta Clinic Group includes four private clinics and has been providing a specialized type of immune-cell therapy $(8,9)$. It has performed immune-cell therapy for patients with advanced pancreatic cancer or as an adjuvant therapy. In this study, pancreatic cancer patients administered with immune-cell therapy were retrospectively analyzed.

\section{Patients and Methods}

Patients. A database of patients administered immune-cell therapy at the clinics of the Seta Clinic Group was searched to identify pancreatic adenocarcinoma patients. A total of 1,040 patients were enrolled in this study and the medical records of those administered $\alpha \beta \mathrm{T}$ cell therapy, DC vaccine therapy, or a combination of both between 1999 and 2015 were retrospectively reviewed. The study protocol was approved by the Research Ethics Committee of Seta Clinic. Available data on age, sex, performance status (PS) score on the Eastern Cooperative Oncology Group (ECOG) scale, metastatic sites, treatments, and vital status were extracted from the medical records of the patients.

Treatment. For $\alpha \beta \mathrm{T}$ cell therapy, activated lymphocytes were generated as previously described (10). In brief, peripheral blood mononuclear cells (PBMCs) were isolated from a patient's peripheral blood using Vacutainer (Becton, Dickinson and Company, Franklin Lakes, NJ, USA). The PBMCs were activated in a culture flask with an immobilized monoclonal antibody to CD3 (JansenKyowa, Tokyo, Japan) in Hymedium 930 (Kohjin Bio, Saitama, Japan) containing $1 \%$ autologous serum. The PBMCs were then cultured for 14 days with $700 \mathrm{IU} / \mathrm{ml}$ recombinant interleukin-2 (IL-2) (Proleukin ${ }^{\circledR}$; Chiron, Amsterdam, the Netherlands). After the culture, $3-10 \times 10^{9}$ cells were harvested and suspended in $100 \mathrm{ml}$ of normal saline for intravenous injection. To prepare a DC vaccine, PBMCs were collected from the patients by leukapheresis and allowed to adhere to a plastic culture flask. The adherent cell fraction was used for DC culture using a medium supplemented with $50 \mathrm{ng} / \mathrm{ml} \mathrm{IL4} \mathrm{(Primmune} \mathrm{Corp.} \mathrm{Osaka,} \mathrm{Japan)} \mathrm{and} 50 \mathrm{ng} / \mathrm{ml}$ granulocyte macrophage colony-stimulating factor (GM-CSF) (Primmune Corp.) for 6 days to generate immature DCs. The DCs were pulsed with antigenic tumor-specific peptides or an autologous tumor lysate and allowed to mature for $24 \mathrm{~h}$. After the culture, $1-10 \times 10^{6}$ mature DCs were harvested and suspended in $1 \mathrm{ml}$ of normal saline for subcutaneous injection, and then cryopreserved until the day of administration. Immune-cell therapy consists of $\alpha \beta$ $\mathrm{T}$ cell therapy, DC vaccine therapy, or both and is commonly administered 6 times every 2 weeks for 3 months as one course.

Assessment. Overall survival (OS) was defined as the length of time from the initial administration of immune-cell therapy to death from any cause and calculated for every patient. Disease-free survival (DFS) was measured from the date of radical surgery to the date of detection of local recurrence/distant metastases or the last administration of immune-cell therapy for recurrence-free patients.

Statistical analyses. OS was examined by the Kaplan-Meier analysis with the log-rank test for univariate analysis and Cox regression methods for multivariate analysis. All statistical analyses were two-sided and performed using JMP, version 11.2.0 for Microsoft Windows 7 (SAS, Cary, NC, USA). Differences were considered statistically significant when $p<0.05$.

\section{Results}

Overall survival. For 17 years from 1999 to 2015, immunecell therapy was administered to 1,056 patients with malignant pancreatic tumors (Figure 1). Among them, 1,040 patients were confirmed by biopsy or suspected from diagnostic imaging findings to have adenocarcinoma, and 16 patients had malignant solid tumors other than adenocarcinoma. Of the 1,040 patients, 990 had advanced or recurrent pancreatic cancer (736 with unresectable pancreatic cancer and 254 with recurrent pancreatic cancer after surgery). Fifty patients received immune-cell therapy as an adjuvant treatment after the curative resection of pancreatic cancer.

In this study, the correlation between OS and various factors including sex, age, PS, distant metastasis, chemotherapy, radiotherapy, and immune-cell therapy were evaluated by univariate analysis and multivariate Cox regression analysis. The median age of the 990 patients (563 males and 427 females) with advanced or recurrent pancreatic cancer was 64 years (range $=27-89$ years). The MST of advanced or recurrent pancreatic cancer was 5.8 months, and the 1-, 3- and 5-year OS rates were $26.8 \%$, $5.3 \%$, and $2.5 \%$, respectively (Figure $2 \mathrm{~A}$ ). There was no significant difference in survival time in relation to sex and age; however, significant differences were observed in relation to PS, distant metastasis, chemotherapy, radiotherapy or immune-cell therapy (Figure 2B-F). The analysis of survival time demonstrated that the MSTs of the patients with PS scores of 0-1 and those with PS scores of 2-4 were 6.4 and 2.4 months, respectively $(p<0.0001)$. The KaplanMeier analysis by the log-rank test showed that MSTs were 4.9 months in the patients with distant metastasis and 9.1 months in those without metastasis $(p<0.0001), 6.0$ months in those with immune-cell therapy with chemotherapy, 2.9 months in those without chemotherapy $(p=0.002), 7.2$ months in those with immune-cell therapy with radiotherapy and 5.4 months in those without radiotherapy $(p=0.006)$. Of the 990 pancreatic cancer patients treated with immune cell therapy, 778 received $\alpha \beta \mathrm{T}$ cell therapy alone and 11 received DC vaccine therapy alone. Two hundred and one patients with advanced or recurrent pancreatic cancer were given combined immune-cell therapy with both $\alpha \beta \mathrm{T}$ cells and DCs $(\alpha \beta$ T cell + DC vaccine $)$. For survival analysis by the type of immune-cell therapy administered, there was a significant difference in MST between patients treated with $\alpha \beta \mathrm{T}$ cell $+\mathrm{DC}$ vaccine and those treated with $\alpha \beta \mathrm{T}$ cells only (8.2 vs. 5.0 months; $p<0.0001)$. Additionally, the 3 -year 


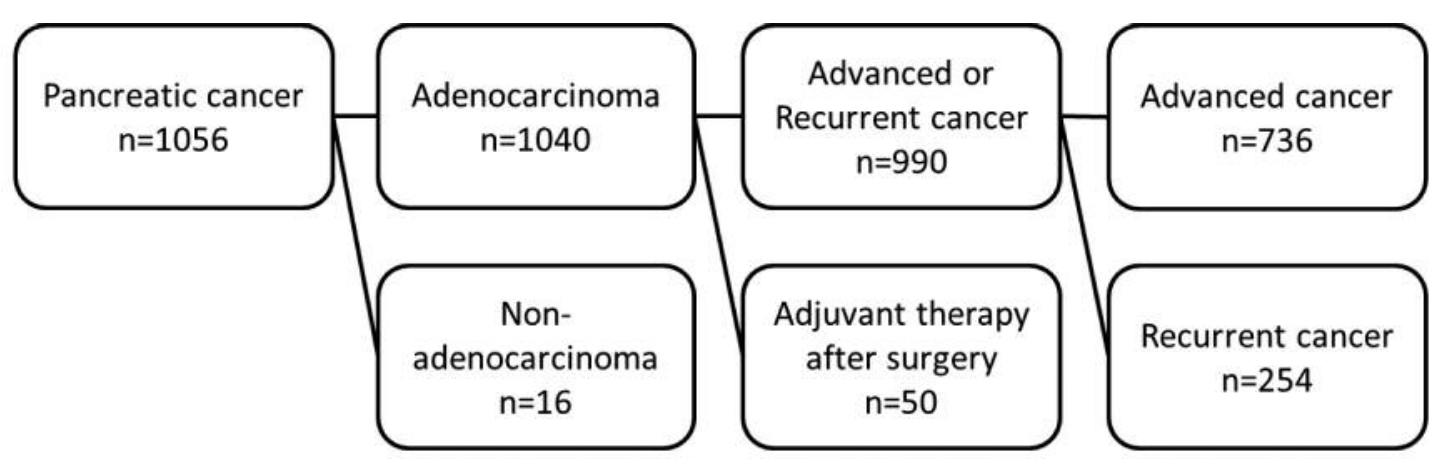

Figure 1. Classification of patients.

A

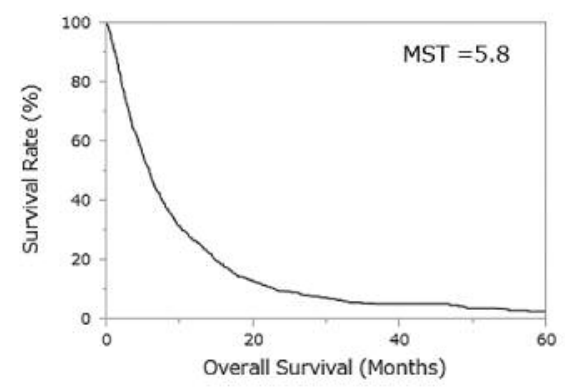

D

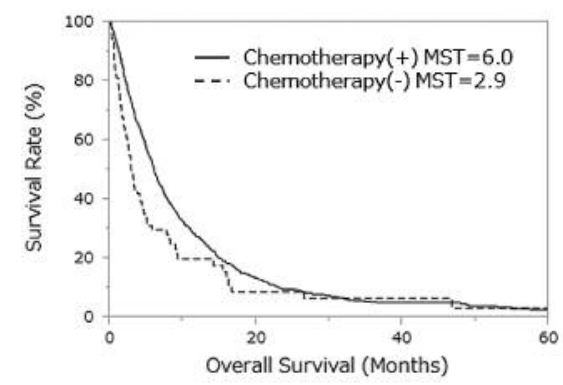

B

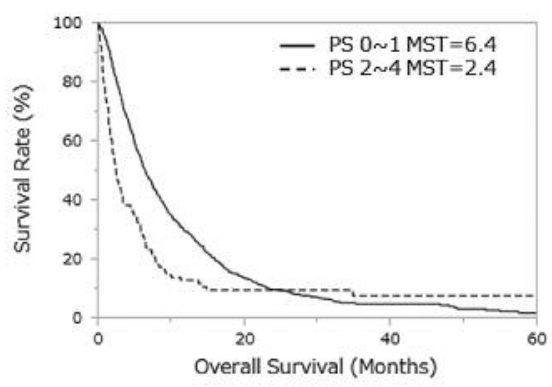

E

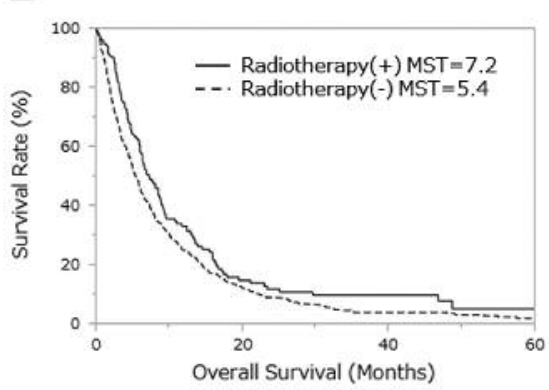

C

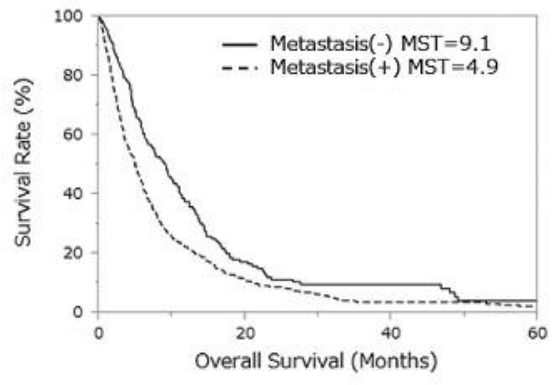

$\mathrm{F}$

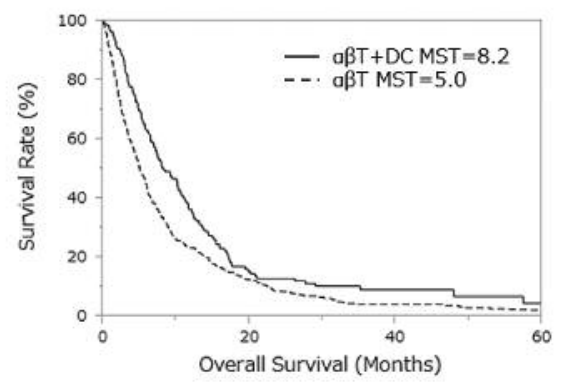

Figure 2. OS rates for all patients (A), in relation to performance status $(B)$, metastasis $(C)$, with/without chemotherapy (D), with/without radiotherapy $(E)$, and type of immune-cell therapy $(F)$. MST: Median survival time; PS: performance status; $\alpha \beta T+D C$ : combination therapy with $\alpha \beta T$ cell and DC vaccine; $\alpha \beta T: \alpha \beta T$ cell therapy.

survival rates of the patients given $\alpha \beta \mathrm{T}$ cell $+\mathrm{DC}$ vaccine and those given $\alpha \beta \mathrm{T}$ cells were $9.3 \%$ and $4.6 \%$, respectively. However, among 11 patients given the DC vaccine alone, none survived longer than 3 years (data not shown).

Univariate and multivariate analyses. The univariate and multivariate analyses demonstrated that PS, distant metastasis, chemotherapy, radiotherapy, and type of immunecell therapy were independent prognostic factors in pancreatic cancer patients (Table I). The prognosis was improved in the pancreatic cancer patients who received immune-cell therapy when they had PS scores of $0-1 \quad(\mathrm{HR}=0.56$; $95 \% \mathrm{CI}=0.46$ $0.68 ; p<0.0001)$. The prognosis was also improved in the patients who received immune-cell therapy combined with chemotherapy $(\mathrm{HR}=0.68 ; 95 \% \mathrm{CI}=0.54-0.87 ; p=0.002)$, and immune-cell therapy combined with radiotherapy $(\mathrm{HR}=0.76 ; 95 \% \mathrm{CI}=0.63-0.93 ; p=0.006)$. Multivariate analysis demonstrated that distant metastasis indicated a poor prognosis in pancreatic cancer patients with immunecell therapy $(\mathrm{HR}=1.62 ; 95 \% \mathrm{CI}=1.37-1.93 ; p<0.0001)$. Additionally, $\alpha \beta \mathrm{T}$ cell $+\mathrm{DC}$ vaccine therapy improved survival in advanced or recurrent pancreatic cancer patients $(\mathrm{HR}=0.69 ; 95 \% \mathrm{CI}=0.57-0.83 ; p<0.0001)$. 
Table I. Patient characteristics and results of univariate and multivariate analyses.

\begin{tabular}{|c|c|c|c|c|c|c|}
\hline & \multirow[b]{2}{*}{$\mathrm{N}$} & \multirow[b]{2}{*}{ MST (Months) } & \multicolumn{2}{|c|}{ Univariate analysis } & \multicolumn{2}{|c|}{ Multivariate analysis } \\
\hline & & & HR $(95 \% \mathrm{CI})$ & $p$-Value & $\mathrm{HR}(95 \% \mathrm{CI})$ & $p$-Value \\
\hline \multicolumn{7}{|l|}{ Age } \\
\hline$\geq 64$ & 533 & 5.8 & $1.08(0.93-1.25)$ & 0.3 & & \\
\hline$<64$ & 457 & 5.8 & 1 & & & \\
\hline \multicolumn{7}{|l|}{ Gender } \\
\hline Male & 563 & 5.6 & $1.01(0.87-1.17)$ & 0.9 & & \\
\hline Female & 427 & 6.0 & 1 & & & \\
\hline \multicolumn{7}{|c|}{ Performance Status Score* } \\
\hline $0-1$ & 814 & 6.4 & $0.56(0.46-0.68)$ & $<0.0001$ & $0.62(0.51-0.76)$ & $<0.0001$ \\
\hline $2-4$ & 163 & 2.4 & 1 & & 1 & \\
\hline \multicolumn{7}{|c|}{ Distant metastasis } \\
\hline Yes & 703 & 4.9 & $1.54(1.31-1.83)$ & $<0.0001$ & $1.62(1.37-1.93)$ & $<0.0001$ \\
\hline No & 287 & 9.1 & 1 & & 1 & \\
\hline \multicolumn{7}{|l|}{ Chemotherapy } \\
\hline Yes & 881 & 6.0 & $0.68(0.54-0.87)$ & 0.002 & $0.69(0.54-0.89)$ & 0.005 \\
\hline No & 109 & 2.9 & 1 & & 1 & \\
\hline \multicolumn{7}{|l|}{ Radiotherapy } \\
\hline Yes & 163 & 7.2 & $0.76(0.63-0.93)$ & 0.006 & $0.81(0.67-1.00)$ & 0.04 \\
\hline No & 827 & 5.4 & 1 & & 1 & \\
\hline \multicolumn{7}{|c|}{ Immune-cell therapy** } \\
\hline$\alpha \beta T$ cell $+\mathrm{DC}$ & 201 & 8.2 & $0.67(0.56-0.80)$ & $<0.0001$ & $0.69(0.57-0.83)$ & $<0.0001$ \\
\hline$\alpha \beta \mathrm{T}$ cell & 778 & 5.0 & 1 & & 1 & \\
\hline Total & & 990 & 5.8 & & & \\
\hline
\end{tabular}

MST: Median survival time; HR: hazard risk; CI: Confidence interval; $\alpha \beta T$ : $\alpha \beta$ T cell therapy; DC: dendritic cell vaccine therapy. *Unknown in 23 patients; **11 patients received only DCs.

Table II. Results of multivariate analysis in relation to with and without distant metastasis.

\begin{tabular}{|c|c|c|c|c|c|c|}
\hline & \multicolumn{3}{|c|}{ Distant metastasis $(+)$} & \multicolumn{3}{|c|}{ Distant metastasis (-) } \\
\hline & $\mathrm{N}$ & HR $(95 \% \mathrm{CI})$ & $p$-Value & $\mathrm{n}$ & HR $(95 \% \mathrm{CI})$ & $p$-Value \\
\hline \multicolumn{7}{|c|}{ Performance Status Score } \\
\hline $0-1$ & 582 & $0.65(0.52-0.84)$ & 0.0008 & 232 & $0.47(0.33-0.70)$ & 0.0002 \\
\hline $2-4$ & 112 & 1 & & 51 & 1 & \\
\hline \multicolumn{7}{|l|}{ Chemotherapy } \\
\hline Yes & 639 & $0.67(0.49-0.94)$ & 0.02 & 242 & $0.71(0.48-1.08)$ & 0.1 \\
\hline No & 64 & 1 & & 45 & 1 & \\
\hline \multicolumn{7}{|l|}{ Radiotherapy } \\
\hline Yes & 101 & $0.79(0.62-1.01)$ & 0.06 & 62 & $0.86(0.60-1.22)$ & 0.4 \\
\hline No & 602 & 1 & & 225 & 1 & \\
\hline \multicolumn{7}{|c|}{ Immune-cell therapy } \\
\hline$\alpha \beta \mathrm{T}$ cell & 545 & 1 & 0.0004 & 233 & 1 & 0.03 \\
\hline$\alpha \beta \mathrm{T}$ cell $+\mathrm{DC}$ & 149 & $0.69(0.56-0.85)$ & & 52 & $0.64(0.42-0.95)$ & \\
\hline
\end{tabular}

HR: Hazard risk; CI: Confidence interval; $\alpha \beta T$ : $\alpha \beta$ T cell therapy; DC: dendritic cell vaccine therapy.

In the prognostic analysis of advanced or recurrent pancreatic cancer based on the presence of distant metastasis, the multivariate analysis showed that PS $(\mathrm{HR}=0.65 ; 95 \% \mathrm{CI}=0.52-0.84 ; p=0.0008)$, chemotherapy
$(\mathrm{HR}=0.67 ; 95 \% \mathrm{CI}=0.49-0.94 ; p=0.02)$, and type of immune-cell therapy $\quad(\mathrm{HR}=0.69 ; \quad 95 \% \mathrm{CI}=0.56-0.85$; $p=0.0004$ ) were independent prognostic factors in advanced or recurrent pancreatic cancer patients (Table II). In locally 
A

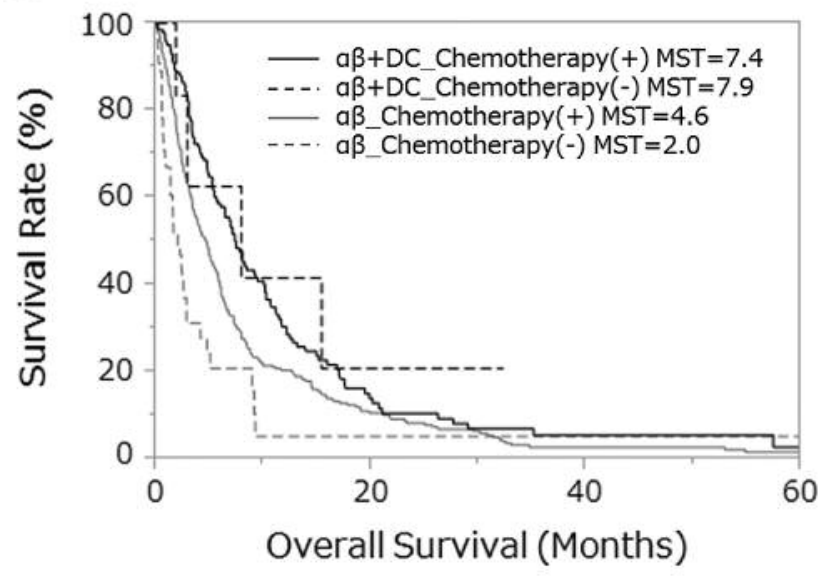

B

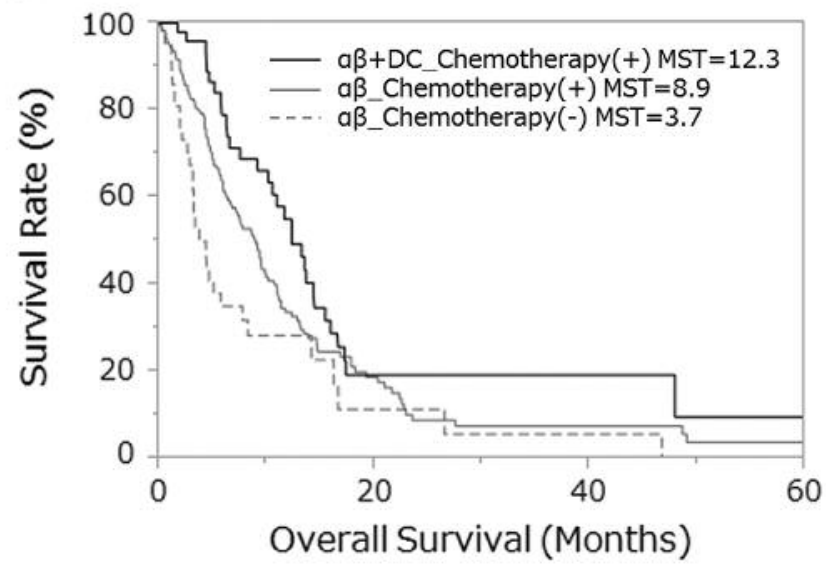

Figure 3. OS rates in relation to type of immune-cell therapy and with/without chemotherapy for patients with metastasis (A) and without metastasis (B). MST: Median survival time. $\alpha \beta T+D C$ : combination therapy of $\alpha \beta$ T cell and DC vaccine. $\alpha \beta T$ : $\alpha \beta T$ cell therapy.

A

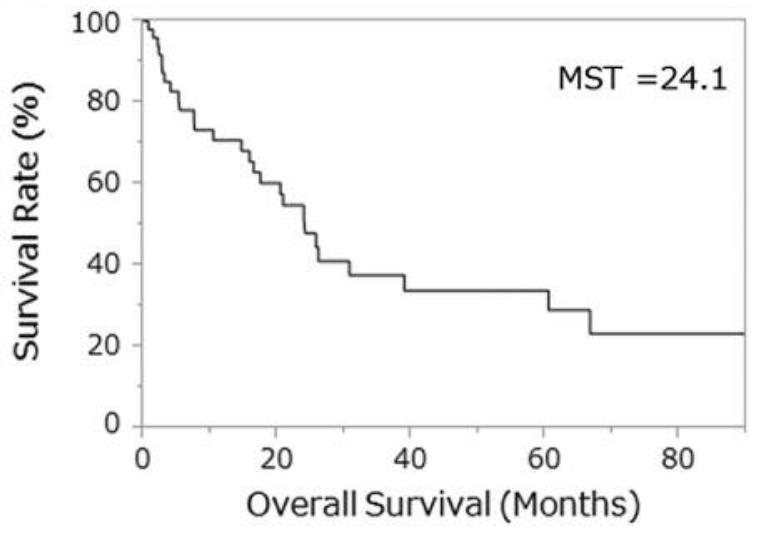

B

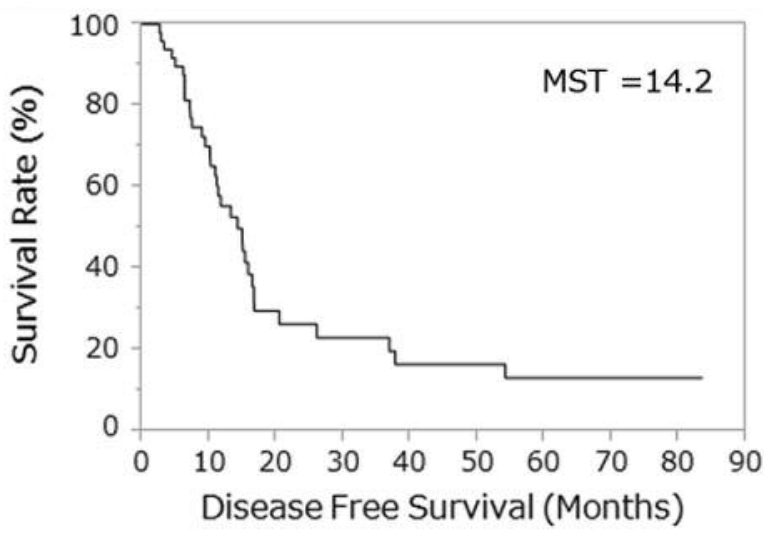

Figure 4. OS rates (A) and DFS rates (B) of patients administered immune cell therapy as adjuvant therapy after surgery. MST: Median survival time.

advanced pancreatic cancer without distant metastasis, PS $(\mathrm{HR}=0.47 ; 95 \% \mathrm{CI}=0.33-0.70 ; p=0.0002)$ and type of immune-cell therapy $(\mathrm{HR}=0.64 ; 95 \% \mathrm{CI}=0.42-0.95 ; p=0.03)$ were significantly associated with superior OS, but not chemotherapy. In the subgroup analysis of pancreatic cancer patients with distant metastasis, the MST of patients administered $\alpha \beta \mathrm{T}$ cell $+\mathrm{DC}$ vaccine therapy combined with chemotherapy was significantly longer than those of patients given $\alpha \beta \mathrm{T}$ cell therapy alone with or without chemotherapy (7.4 months vs. 4.6 months or 2.0 months, respectively; $p<0.0001$ ) (Figure $3 \mathrm{~A}$ ). In locally advanced pancreatic cancer without distant metastasis, the KaplanMeier analysis demonstrated that the combination of $\alpha \beta \mathrm{T}$ cell therapy, DC vaccine therapy, and chemotherapy provided a better survival benefit than $\alpha \beta \mathrm{T}$ cell therapy with or without chemotherapy (MST of 12.3 months vs. 8.9 months or 3.7 months, respectively; Figure 3B). Among the patients with advanced or recurrent pancreatic cancer, only 5 were given $\alpha \beta$ T cell + DC therapy without chemotherapy (4 patients with distant metastasis and 1 patient with locally advanced pancreatic cancer).

Survival analysis of resected pancreatic cancer patients. Fifty pancreatic cancer patients were administered immunecell therapy as an adjuvant therapy after the curative resection of tumor. Of these 50 patients, on the basis of the General Rules for the Study of Pancreatic Cancer of Japan Pancreatic Society, 1 was assessed to be in stage I, 1 in 
stage II, 18 in stage III, 17 in stage IVa, 6 in stage IVb, and 7 in an unknown stage at the time of tumor resection. Fortytwo patients received both adjuvant chemotherapy and immune-cell therapy and 8 received immune-cell therapy alone. For the 42 patients, the median OS and DFS were 24.1 and 14.2 months, the 3- and 5-year OS ratios were $37.7 \%$ and $33.9 \%$, and the 3 - and 5-year DFS ratios were $23.1 \%$ and $13.2 \%$, respectively (Figure 4 ). In addition, the median OS of the 42 patients who received both chemotherapy and immune-cell therapy was 25.7 months, compared with 10.4 months in the patients who received immune-cell therapy alone (data not shown).

\section{Discussion}

Even though surgery is a reliable method for the treatment of clinically resectable tumor, the resection rate of pancreatic cancer remains far lower than those of other types of solid tumor. Additionally, pancreatic cancer commonly recurs after the resection, which is one of the reasons for the poor prognosis of the disease. We have been performing immunecell therapy for patients with various malignant tumors since 1999. In this study, 990 advanced or recurrent and 50 postoperative pancreatic cancer patients administered immune-cell therapy were analyzed.

In the comparison between immune-cell therapy alone and that combined with other treatments, several studies demonstrated that a combination therapy showed better therapeutic effects than immune-cell therapy alone. In this study, combination of immune-cell therapy and chemotherapy provided a survival benefit in the advanced or recurrent pancreatic cancer patients. In 2011, Hontscha et al. (11) searched for 11 clinical trials of cytokineinduced killer (CIK) cells used as a type of immune-cell therapy. The study showed the following clinical responses of 384 patients with various cancers: 24 patients showed a complete response, 27 a partial response, and 40 a minor response, and 161 had a stable disease and 129 had a progressive disease. Additionally, the DFS was significantly longer in patients treated with CIK cells than in those without CIK cell treatment (11). In another study of immune-cell therapy, 255 inoperable pancreatic cancer patients administered a standard chemotherapy combined with peptide-pulsed DC vaccine therapy were analyzed. The study showed that the MST from diagnosis was 16.5 months, which was longer than that of the standard chemotherapy (about 10 months) (12). Besides these studies, as a postoperative adjuvant therapy for resectable pancreatic cancer patients, the combination of adoptive immune-cell therapy and GEM prevented liver metastasis and local recurrence and improved DFS (15.8 months) (13). In our study, the combination of immune-cell therapy and chemotherapy extended the MST from the first administration of immune-cell therapy by 5.8 months compared with immune-cell therapy alone (2.9 months).

DCs and $\alpha \beta \mathrm{T}$ cells are mainly used in immune-cell therapy; however, it is necessary to consider how this treatment modality should be combined with other cancer treatment modalities. In a study of advanced pancreatic cancer patients, the combination of DCs, CIK cells, and chemotherapy produced significantly longer median OS and PFS (212 and 136 days) than combined DC and CIK cell therapy (128 and 85 days), chemotherapy alone (141 and 92 days), and supportive care alone (52 and 43 days). Moreover, the disease control rates of these treatment modalities (combination of DCs, CIK cells, and chemotherapy; combined DC and CIK cell therapy; chemotherapy alone; and supportive care alone) were $80 \%, 45 \%, 50 \%$, and $0 \%$, respectively (14). It is considered that the concurrent administration of DC vaccine and CIK cells provided treatment benefits possibly via the immune elicitation at multiple steps in the cancer-immunity cycle. In our study, the MST was 5.0 months in patients with $\alpha \beta \mathrm{T}$ cell therapy, whereas none of the patients treated with DC vaccines alone survived longer than 3 years. In the combination of $\alpha \beta \mathrm{T}$ cells and DC vaccine, on the other hand, a significant increase in MST of 8.2 months was indicated. It is suggested that the combination of DC vaccine and $\alpha \beta \mathrm{T}$ cells for immune-cell therapy could potentially provide a survival benefit in pancreatic cancer patients.

Theurich et al. surveyed the efficiency of metastatic control by local peripheral treatments (LPTs) such as radiotherapy (15). Retrospective analysis of 127 melanoma patients treated with either ipilimumab plus LPT or ipilimumab only revealed that the combination of ipilimumab with LPT resulted in a significantly better median OS (93 weeks vs. 42 weeks). They supposed that the mechanism underlying this outcome is as follows. First, radiotherapy can induce an immunogenic type of cancer cell death associated with antigen release, cytokine production, and complement activation, finally generating in situ a tumor vaccine. Second, radiotherapy increases MHC class I expression levels and induces immune cell migration into the tumor microenvironment. Third, radiotherapy enhances the diversity of the T-cell receptor repertoire of intratumoral $\mathrm{T}$ cells. All these mechanisms together can contribute to enhanced systemic immune responses after local radiotherapy. It can also be applicable to pancreatic cancer; that is, metastatic control can lead to better treatment effectiveness. In this study, the MST of those treated with radiotherapy was 7.2 months and it is significantly longer than 5.4 months in those treated without radiotherapy, as determined by univariate analysis, as shown in the Radiotherapy item (Yes/No) in Table I. It is considered that radiotherapy enhances the immune system by decreasing tumor volume and enhancing antigen presentation. 
Although the combination of chemotherapy and immunecell therapy was previously considered undesirable, it was gradually clarified that this combination leads to better effects, as mentioned above. These better effects can be explained by the reinforcement of the immune system via the actions of anticancer agents, for example, suppression of Treg induction by GEM (16), inhibition of PDL2 expression by oxaliplatin (17), and increase in MHC class I expression level by fluorouracil (18).

The subsets of $\mathrm{T}$ lymphocytes before and after the immune-cell therapy were analyzed in several studies. In a study of advanced pancreatic cancer patients, the numbers of $\mathrm{CD}^{+}, \mathrm{CD}^{+} / \mathrm{CD}^{+}$, and $\mathrm{CD} 8^{+} / \mathrm{CD} 28^{+} \mathrm{T}$ cell subsets increased, whereas those of $\mathrm{CD}^{+} / \mathrm{CD}^{+}$and $\mathrm{CD}^{+} / \mathrm{CD} 25^{+}$ cell subsets were significantly decreased after DC-CIK cell therapy (14). Another study showed that the $\mathrm{CD}^{+} /$Treg ratio significantly increased in SD patients after the therapy with the combination of intratumoral injection of DC vaccine, GEM, and $\alpha \beta \mathrm{T}$ cells in locally advanced pancreatic cancer (7). It showed that changes in $\mathrm{CD}^{+} /$Treg ratio are beneficial for immune-cell therapy. These data indicated that DC-CIK infusions changed the ratios of the $\mathrm{T}$ cell subsets. This immune-cell therapy was found to improve the impairment in the immune system and extended the OS in patients with advanced cancer. The changes in the ratio of $\mathrm{T}$ cell subsets represent a novel independent predictor of progression-free survival. The possible mechanism underlying the antitumor effect of immune-cell therapy is considered to be as follows: increase in cytokine secretion, improvement of immune function, and induction of apoptosis of cancer cells.

In conclusion, a better prognosis could be obtained with better PS by the combination of $\alpha \beta \mathrm{T}$ cell therapy, DC vaccine therapy and chemotherapy at an early stage with the normal immune-cell function preserved. However, in order to establish a comprehensive immunotherapy for pancreatic cancer, it is necessary to conduct clinical trials using various treatments at various timings, such as immune-cell therapy, chemotherapy, radiotherapy or the use of immune checkpoint inhibitors.

\section{Conflicts of Interest}

The Authors affirm that there are no potential conflicts of interest in relation to the present study.

\section{References}

1 Gillen S, Schuster T, Meyer Zum Buschenfelde C, Friess H and Kleeff J: Preoperative/neoadjuvant therapy in pancreatic cancer: a systematic review and meta-analysis of response and resection percentages. PLoS med 7: e1000267, 2010.

2 Burris HA, 3rd, Moore MJ, Andersen J, Green MR, Rothenberg ML, Modiano MR, Cripps MC, Portenoy RK, Storniolo AM,
Tarassoff P, Nelson R, Dorr FA, Stephens CD and Von Hoff DD: Improvements in survival and clinical benefit with gemcitabine as first-line therapy for patients with advanced pancreas cancer: a randomized trial. J Clin Oncol 15: 2403-2413, 1997.

3 Conroy T, Desseigne F, Ychou M, Bouche O, Guimbaud R, Becouarn Y, Adenis A, Raoul JL, Gourgou-Bourgade S, de la Fouchardiere C, Bennouna J, Bachet JB, Khemissa-Akouz F, Pere-Verge D, Delbaldo C, Assenat E, Chauffert B, Michel P, Montoto-Grillot $\mathrm{C}$ and Ducreux M: FOLFIRINOX versus gemcitabine for metastatic pancreatic cancer. N Engl J Med 364: 1817-1825, 2011.

4 Von Hoff DD, Ervin T, Arena FP, Chiorean EG, Infante J, Moore M, Seay T, Tjulandin SA, Ma WW, Saleh MN, Harris M, Reni M, Dowden S, Laheru D, Bahary N, Ramanathan RK, Tabernero J, Hidalgo M, Goldstein D, Van Cutsem E, Wei X, Iglesias J and Renschler MF: Increased survival in pancreatic cancer with nabpaclitaxel plus gemcitabine. N Engl J Med 369: 1691-1703, 2013.

5 Kimura H, Matsui Y, Ishikawa A, Nakajima T, Yoshino M and Sakairi Y: Randomized controlled phase III trial of adjuvant chemo-immunotherapy with activated killer $\mathrm{T}$ cells and dendritic cells in patients with resected primary lung cancer. Cancer Immunol Immunother 64: 51-59, 2015.

6 Iwai K, Soejima K, Kudoh S, Umezato Y, Kaneko T, Yoshimori K, Tokuda H, Yamaguchi T, Mizoo A, Setoguchi Y, Kamigaki T, Fujimoto K and Goto S: Extended survival observed in adoptive activated $\mathrm{T}$ lymphocyte immunotherapy for advanced lung cancer: results of a multicenter historical cohort study. Cancer Immunol Immunother 61: 1781-1790, 2012.

7 Hirooka Y, Kawashima H, Ohno E, Ishikawa T, Kamigaki T, Goto S, Takahara $\mathrm{M}$ and Goto $\mathrm{H}$ : Comprehensive immunotherapy combined with intratumoral injection of zoledronate-pulsed dendritic cells, intravenous adoptive activated $\mathrm{T}$ lymphocyte and gemcitabine in unresectable locally advanced pancreatic carcinoma: a phase I/II trial. Oncotarget 9: 2838-2847, 2018.

8 Egawa K: Immuno-cell therapy of cancer in Japan. Anticancer Res 24: 3321-3326, 2004.

9 Kamigaki T, Matsuda E, Okada S, Naitoh K, Kondo T, Ibe H, Maekawa R, and Goto S: Prospective evaluation of safety of immune-cell therapy for patients with various types of advanced cancer. Anticancer Res 34: 4601-4607, 2014.

10 Takimoto R, Kamigaki T, Okada S, Matsuda E, Ibe H, Oguma E, Naitoh K, Makita $\mathrm{K}$ and Goto S: Efficacy of adoptive immune-cell therapy in patients with advanced gastric cancer: A retrospective study. Anticancer Res 37: 3947-3954, 2017.

11 Hontscha C, Borck Y, Zhou H, Messmer D and Schmidt-Wolf IG: Clinical trials on CIK cells: first report of the international registry on CIK cells (IRCC). J Cancer Res Clin Oncol 137: 305-310, 2011.

12 Kobayashi M, Shimodaira S, Nagai K, Ogasawara M, Takahashi H, Abe H, Tanii M, Okamoto M, Tsujitani S, Yusa S, Ishidao T, Kishimoto J, Shibamoto Y, Nagaya M and Yonemitsu Y: Prognostic factors related to add-on dendritic cell vaccines on patients with inoperable pancreatic cancer receiving chemotherapy: a multicenter analysis. Cancer Immunol Immunother 63: 797-806, 2014.

13 Takahashi H, Okamoto M, Shimodaira S, Tsujitani S, Nagaya M, Ishidao T, Kishimoto J and Yonemitsu Y: Impact of dendritic cell vaccines pulsed with Wilms' tumour-1 peptide antigen on the survival of patients with advanced non-small cell lung cancers. Eur J Cancer 49: 852-859, 2013. 
14 Jiang N, Qiao G, Wang X, Morse MA, Gwin WR, Zhou L, Song Y, Zhao Y, Chen F, Zhou X, Huang L, Hobeika A, Yi X, Xia X, Guan Y, Song J, Ren J and Lyerly HK: Dendritic cell/cytokineinduced killer cell immunotherapy combined with S-1 in patients with advanced pancreatic cancer: A prospective study. Clin Cancer Res 23: 5066-5073, 2017.

15 Theurich S, Rothschild SI, Hoffmann M, Fabri M, Sommer A, Garcia-Marquez M, Thelen M, Schill C, Merki R, Schmid T, Koeberle D, Zippelius A, Baues C, Mauch C, Tigges C, Kreuter A, Borggrefe J, von Bergwelt-Baildon M and Schlaak M: Local tumor treatment in combination with systemic ipilimumab immunotherapy prolongs overall survival in patients with advanced malignant melanoma. Cancer Immunol Res 4: 744-754, 2016.

16 Galluzzi L, Senovilla L, Zitvogel L and Kroemer G: The secret ally: immunostimulation by anticancer drugs. Nat Rev Drug Discov 11: 215-233, 2012.
17 Chang JH, Jiang Y and Pillarisetty VG: Role of immune cells in pancreatic cancer from bench to clinical application: An updated review. Medicine 95: e5541, 2016.

18 Matsui H, Hazama S, Sakamoto K, Shindo Y, Kanekiyo S, Nakashima M, Matsukuma S, Tokuhisa Y, Iida M, Suzuki N, Yoshimura K, Takeda S, Ueno T, Yoshino S, Oka M and Nagano $\mathrm{H}$ : Postoperative adjuvant therapy for resectable pancreatic cancer with gemcitabine and adoptive immunotherapy. Pancreas 46: 994-1002, 2017.
Received April 11, 2018

Revised June 7, 2018

Accepted June 18, 2018 